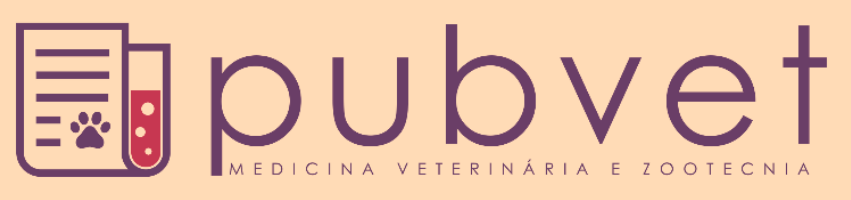

https://doi.org/10.31533/pubvet.v13n12a467.1-13

\title{
Fundamentos das perícias cível e criminal na síndrome de maus- tratos em bovinos
}

\author{
Jackson Barros do Amaral ${ }^{1 *} \bullet$, Tália Missen Tremori ${ }^{2} \bullet$, Ana Carolina Lopes Batista ${ }^{3} \bullet$, Elaine \\ Jaqueline Hans $^{40}$, Luísa de Oliveira Lisboa ${ }^{50}$
}

\begin{abstract}
${ }^{1}$ Médico Veterinário, Pesquisador Científico, Secretaria de Agricultura e Abastecimento - SAA do Estado de São Paulo, Instituto de Zootecnia - Centro de Pesquisa de Bovinos de Leite, Rua Heitor Penteado, 56, CP 60, Nova Odessa-SP, Brasil, CEP 13380-011.

${ }^{2}$ Médica Veterinária, Doutora pela Faculdade de Medicina Veterinária e Zootecnia - FMVZ da Universidade Estadual Paulista - UNESP “Júlio de Mesquita Filho" Distrito de Rubião Jr., s/n-Botucatu, SP, CEP 18618-970, Doutora pela Universidad de Salamanca, Espanha.

${ }^{3}$ Bolsista - Centro de Integração Empresa-Escola/Instituto de Zootecnia - CIEE/IZ, Graduanda de Medicina Veterinária, Centro Universitário de Jaguariúna - UNIFAJ, Rodovia Dr. Governador Adhemar Pereira de Barros, Jaguariúna/SP, Km 127, s/n, CEP $13820-000$.

${ }^{4}$ Graduanda de Medicina Veterinária, Centro Universitário de Jaguariúna - UNIFAJ, Rodovia Dr. Governador Adhemar Pereira de Barros, Jaguariúna/SP, Km 127, s/n, CEP 13820-000.

${ }^{5}$ Médica Veterinária, Investigadora da Delegacia Especializada em Crimes Contra a Fauna - Polícia Civil de Minas Gerais - PCMG,

*Autor para correspondência, e-mail: jackson@iz.sp.gov.br
\end{abstract}

Resumo. Embora pouco discutida e explorada a investigação forense torna-se uma demanda inovadora e relevante na perícia em crimes de maus-tratos praticados contra bovinos. Para a constatação do crime, além do baixo grau de bem-estar também é necessário à comprovação do dolo pelo agente. Na esfera cível, a imperícia, a imprudência e a negligência são conhecidas como modalidades de culpa ou expressão da atitude delituosa e as transgressões resultantes destes fundamentos apresentam como causa elementar, faltando, às vezes, consciência do infrator. Os enfrentamentos judiciais relacionados a bovinos são raros, embora nos últimos tempos tendam aumentar e os erros profissionais referentes à assistência a saúde e a reprodução, que estão vinculadas à responsabilidade civil, são controlados pelo Código de Defesa do Consumidor (CDC) e pelo Código Civil. Ademais, os médicos veterinários ainda estão sujeitos à fiscalização da sua conduta profissional de acordo com o Código de Ética do Médico Veterinário (CEMV). O presente artigo tem o objetivo discutir os princípios e fundamentos da Medicina Veterinária Legal na realização de perícias e exame de corpo de delito como requisitos necessários para elaboração de laudo pericial, em especial nos casos de maus-tratos em bovinos. Além de propor um protocolo específico para avaliação de bem-estar em bovinos como ferramenta auxiliar na elaboração de laudos periciais. Diante do exposto, o médico veterinário deve-se precaver elaborando prontuários de pacientes individual e de rebanho, tendo posturas éticas e assumindo o compromisso com o bem-estar animal.

Palavras chave: Bem-estar animal, bovinocultura, criminalística, corpo de delito, perícia veterinária

\section{Fundamentals of civil and criminal expertise in welfare and mistreatment syndrome in cattle}

Abstract. Although little discussed and explored forensic investigation becomes an innovative and relevant demand for expertise in crimes of maltreatment against cattle. For the finding of crime, besides the low degree of well-being is also necessary to prove the intent by the agent. In the civil sphere, malpractice, recklessness and neglect are known as modalities of guilt or expression of wrongdoing and the transgressions resulting from these grounds present as an elementary cause, sometimes lacking the conscience of the offender. Lawsuits related to cattle are rare, although in recent times they tend to increase and 
professional errors in health care and reproduction, which are linked to civil liability, are controlled by the Consumer Protection Code (CDC) and the Civil Code. In addition, veterinarians are still subject to supervision of their professional conduct in accordance with the Veterinary Doctor's Code of Ethics (CEMV). The aim of this article is to discuss the principles and fundamentals of Forensic Veterinary Medicine in conducting expertise and examination of body of crime as necessary requirements for the preparation of expert report, especially in cases of maltreatment in cattle. In addition to proposing a specific protocol for welfare assessment in cattle as an auxiliary tool in the preparation of expert reports. Given the above, the veterinarian should be careful in preparing individual patient and herd records, taking ethical attitudes and making a commitment to animal welfare.

Keywords: animal welfare, cattle production, criminalistic, corpus of delicti, veterinary expertise

\title{
Fundamentos de la investigacion civil y penal en el bienestar y el síndrome de maltrato en ganado
}

\begin{abstract}
Resumen. Aunque poco discutido y explorado, la investigación forense se convierte en una demanda innovadora y relevante de experiencia en delitos de maltrato contra el ganado bovinp. Para encontrar el delito, además del bajo grado de bienestar, también es necesario demostrar la intención del agente. En la esfera civil, la mala práctica, la imprudencia y la negligencia se conocen como modalidades de culpa o expresión de irregularidades y las transgresiones resultantes de estos motivos se presentan como una causa elemental, a veces sin la conciencia del delincuente. Los juicios relacionados con el ganado son raros, aunque en los últimos tiempos tendieron a aumentar y los errores profesionales en el cuidado de la salud y la reproducción, que están vinculados a la responsabilidad civil, están controlados por el Código de Protección al Consumidor (CDC) y el Código Civil. Además, los veterinarios aún están sujetos a la supervisión de su conducta profesional de acuerdo con el Código de Ética del Médico Veterinario (CEMV). El objetivo de este artículo es discutir los principios y fundamentos de la Medicina Veterinaria Forense en la realización de la experiencia y el examen del cuerpo del delito como requisitos necesarios para la preparación del informe pericial, especialmente en casos de maltrato en el ganado. Además de proponer un protocolo específico para la evaluación del bienestar en el ganado como herramienta auxiliar en la preparación de informes de expertos. Dado lo anterior, el veterinario debe tener cuidado al preparar los registros individuales de pacientes y rebaños, adoptar actitudes éticas y comprometerse con el bienestar animal.
\end{abstract}

Palabras clave: Bienestar animal, criminalística, cuerpo de delito, pericia veterinaria, ganaderia

\section{Introdução}

O progresso e a relevância concedida pela sociedade aos animais e seus direitos vem crescendo nos últimos anos e a Medicina Veterinária Legal (MVL) vem se destacando (Slowinski et al., 2016). A MVL constitui especialidade da profissão que utiliza conhecimentos das ciências veterinárias direcionados ao direito e a justiça (Maiorka, 2016). Consistem nos conceitos, competências, tecnologia e métodos próprios da Medicina Veterinária, acrescidos às ciências afins, aplicados aos esclarecimentos de temas judiciais (Garcia, 2017). Na década de 60, o livro Animal Machines de Ruth Harrison, que tornou público o sofrimento dos animais de produção, foi um marco para o início da era do bem-estar animal. Mas somente na década de 1990 aconteceram as primeiras publicações sobre maus-tratos aos animais em revistas de criminologia (Garcia, 2017). A atenção envolvendo o bem-estar animal denota um progresso na questão social, política, ética, legislativa e científica, na relação homem e animais, existindo também interações negativas como os maus-tratos contra os animais (Hammerschmidt \& Molento, 2017). Maustratos a animais são frequentes e o médico veterinário representa o profissional habilitado para realizar perícias, utilizando-se conhecimentos técnico-científicos para elucidar os vestígios e expor os aspectos na presença de criminosos ou suspeitos, sendo o exame de corpo de delito o procedimento de destaque para analisar o local do crime (Tremori \& Rocha, 2013). Uma vez reconhecida à conduta culposa do profissional, seja por negligência, imperícia ou imprudência, o mesmo terá que responder no âmbito 
administrativo, ou até mesmo no âmbito jurídico (Slowinski et al., 2016). O conceito de síndrome é caracterizado como um conjunto de sintomas clínicos, apresentando múltiplas causas que caracterizam determinadas enfermidades ou lesões e quando identificada constitui o diagnóstico sindrômico. Contudo, em alguns casos a síndrome não apresenta uma entidade mórbida, e sua identificação é fundamental para orientar o diagnóstico e investigações futuras (Feitosa, 2014). Dessa forma, é de suma importância uma abordagem sistêmica, na qual são avaliados o animal, o rebanho, o ambiente e o manejo. A União Europeia criou o Welfare Quality Project, identificando quatro categorias para a avaliação do bem-estar de animais de produção, mas que tem sido usado como exemplo para a construção de protocolos de avaliação do nível de bem-estar para outras espécies animais: nutricional, ambiental (conforto), saúde e comportamental (Garcia, 2017). Este artigo tem como objetivo discutir fundamentos do bem-estar animal, da clínica médica, da clínica cirúrgica e das patologias forenses na elaboração de documentos médicos legais necessários para investigações judiciais em situações envolvendo maus-tratos em bovinos, constatação de nexo de casualidade para compor ações cíveis de reparação de danos materiais e/ou morais e também na conduta ética e responsabilidade técnica do médico veterinário.

\section{Desenvolvimento}

As ciências forenses exercidas no sistema de desenvolvimento e transmissão de conhecimentos científicos e tecnológicos, nas áreas de conhecimentos com o propósito de aplicação na investigação de vestígios, com fins de responder indagações científicas de interesse da justiça. Constituem um conjunto de áreas que se reúnem para obter o mesmo objetivo nas demandas judiciais (Velho et al., 2017). A palavra perícia retrata expertise e representa a forma de prova relevante para o Poder Judiciário ou Ministério Público, requerido em grande escala em processos civis e penais e devem ser conduzidas por especialistas de áreas especializadas ou por profissionais capacitados (Conceição et al., 2017). Por definição a perícia pode ser conceituada como termo genérico reservado a realização de vários tipos de exames especializados, com a finalidade de elucidar a ocorrência de fatos do ponto de vista científico (Velho et al., 2017). O avanço e a importância dada pela sociedade aos animais, bem como aos seus direitos vem crescendo nos últimos anos, principalmente na área da Medicina Veterinária Legal. No ambiente clínico-hospitalar o médico veterinário tem papel fundamental na responsabilidade técnica, onde se torna imprescindível empenho para alcançar soluções específicas nos seus ofícios. Neste contexto, o médico veterinário precisa estar em alerta ao Código de Ética e Deontologia Veterinária, e quanto a Legislação do CFMV e ao Código de Defesa do Consumidor e Código Civil (Slowinski et al., 2016). Analisando o artigo $14^{\circ}$ do Código de Defesa do Consumidor, Lei $n^{\circ} 8.078 / 90$, o médico veterinário prestador de serviço responde, independentemente da existência de culpa, pela reparação dos danos causados aos consumidores por defeitos relativos à prestação dos serviços, bem como por informações insuficientes ou inadequadas sobre sua função e riscos. Em animais de produção, incluindo os bovinos, sistemas com baixo bem-estar constituem uma preocupação de ordem mundial. No Brasil, os maus-tratos aos animais é crime previsto na Lei de Crimes Ambientais (LCA), a Lei nº 9.605/98, na seção específica de crimes contra a fauna. Os esclarecimentos de crimes envolvendo animais são considerados tema de grande destaque, tanto no meio jurídico como no acadêmico-científico. Além disso, a compreensão sobre os direitos dos animais, bem-estar animal, preservação do meio ambiente, criminalística, legislação e inspeção de produtos de origem animal vêm crescendo, havendo necessidade da aplicação da medicina veterinária legal (Tremori et al., 2018). Segundo o Direito, as perícias são classificadas em perícia cível, criminal e trabalhista, sendo a cível e criminal as principais modalidades de perícias realizadas na medicina veterinária legal (Conceição et al., 2017). Tanto na esfera cível ou criminal as perícias têm por objetivo esclarecer os fatos e expor a verdade ao processo, tanto no plano judicial como no administrativo (Figueiredo, 2009).

\section{Perícia cível}

Por definição a perícia cível é aquela que investiga enfrentamentos judiciais na área patrimonial e/ou pecuniária (Figueiredo, 2009). Este tipo de perícia é realizado por diversos profissionais, incluindo o médico veterinário, os quais são solicitados por autoridades judiciais para esclarecer fatos na qual é necessário ressarcimento, dano moral, material, patrimonial e/ou pecuniário. A perícia veterinária deve ser realizada por médico veterinário, o qual utiliza suas especialidades para realização de exames 
detalhados, elaboração de documentos, pesquisa em animais vivos ou mortos e na elaboração de provas técnico-científicas indispensáveis para elaboração do laudo pericial (Conceição et al., 2017). De acordo com a Lei $\mathrm{n}^{\circ} 5.517 / 68$, art. 5, Alíneas "g" e "h" o médico veterinário pode ser legalmente um perito, o qual está amparado pela lei (Brasil, 1968) e pela Resolução n 722/02, Art. 28, Incisos I, II e III, do Código de Ética do Conselho Federal de Medicina Veterinária (Brasil, 2002). No novo Código de Processo Civil (CPC), Lei n ${ }^{\circ} 13.105 / 15$, a prova pericial é tratada do artigo 464 a 480 onde constam os requisitos e formalidades que devem ser seguidos (Brasil, 2015).

\section{Perícia criminal}

Do ponto de vista conceitual em Direito crime é toda atitude específica, prevista na lei, ilícita, contra a lei, condenável e cometida por um ser humano. Portanto, uma atuação contrária ao Código Penal, consequentemente, sujeita a condenação (Reis, 2017). O perito criminal ou penal configura o profissional que tem como atribuição de realizar a investigação objetiva, buscando auxiliar para que a ocorrência do fato seja exposta, fundamentando nos aspectos técnico-científicos para direcionar a uma conclusão justa de uma ocorrência. As atividades do perito criminal são de fundamental importância e imprescindível na elaboração da prova material, das coletas dos exames, do esclarecimento da finalização do laudo pericial. O perito criminal deve estar ciente do relevante desafio no enfrentamento com os bens de maior destaque do ser humano que é a liberdade e a vida (Santiago, 2014). A perícia criminal pesquisa as infrações penais, onde o Estado assume a defesa da vítima em nome da sociedade, devendo esta ser conduzida por peritos oficiais, que são profissionais de nível superior, ingressado no serviço público mediante concurso, com função específica de fazer perícias (Figueiredo, 2009). Na falta de peritos oficiais este código prevê atuação de peritos não oficiais ( $A d h o c)$ designados para realização de perícias criminais, não sendo incomum a necessidade de designação de médicos veterinários da área de clínica médica, funcionários públicos, docentes ou pesquisadores para atuarem como peritos Ad hoc em situações específicas.

O laudo pericial criminal elaborado nestas circunstâncias destina-se à esfera criminal, com formalidades e regulamentos notadamente procedentes do Código de Processo Penal (CPP). De acordo com o CPP, no momento que na investigação encontram-se vestígios materiais deixados pelo criminoso, torna-se obrigatório a realização de perícia, ou seja, o exame de corpo de delito (Velho et al., 2017). O médico veterinário pode atuar como assistente técnico, da confiança das partes nos processos judiciais, nas áreas cíveis ou criminais, tendo como atribuições avaliar e emitir pareceres relacionados aos exames realizados pelos peritos (Tostes \& Reis, 2017).

\section{Exame de corpo de delito}

Do ponto de vista etimológico o termo "corpo de delito" revela o fato material que se fundamenta a prova de um crime, neste caso não podendo confundir com o corpo da suposta vítima. O corpo de delito pode ser direto quando os objetos de provas são vestígios materiais, como peças, objeto, armas brancas, arma de fogo, pessoas e outros e indireto quando os objetos de provas são provas testemunhais, como receituários, prontuários médicos, filmagens, fotografias, entre outros (Rocha, 2017). O termo "corpo de delito" retrata episódio concreto que se fundamenta em comprovação de um crime, revelando a realidade de vestígios da lesão hipoteticamente criminosa, assim como do âmbito ou mecanismo que impulsionou. O exame de corpo de delito deve ser realizado por profissionais especializados, competentes, pelo fato de ser a fundamentação residual de determinado crime. De acordo com o CPP o exame de corpo de delito deve ser realizado por peritos oficiais ou não oficiais, devendo este último ser idôneo, ter curso superior, notadamente na área na qual está assessorando a autoridade judicial (Rocha, 2017). De acordo com o CPP o exame de corpo de delito é obrigatório por lei, sempre que infração deixar vestígios, não podendo supri-lo a confissão do acusado. Quando na instância criminal, o exame médico-legal é designado de exame de corpo de delito, o qual tem a finalidade de investigar elementos que possam auxiliar evidências da ocorrência de um crime (Guimarães, 2017). No art. 161, do CPP o exame de corpo de delito poderá ser feito em qualquer dia e a qualquer hora (Brasil, 1941). A ausência do corpo de delito pode levar à nulidade de uma ação penal (Velho et al., 2017). A traumatologia forense é um ramo da medicina legal que classifica as lesões que afetam a integridade física dos indivíduos, com danos à saúde, podendo provocar até mesmo a morte (Costa \& Costa, 2015). As ocorrências da maioria das lesões causadas nos animais são comumente interpretadas como maus-tratos, no entanto, esta 
condição pode confundir o julgamento e compreensão do magistrado, tendo em vista a complexidade do diagnóstico e definição de maus-tratos (Tremori et al., 2018). Na Resolução CFMV nº 1.236, de 26 de Outubro de 2018, no art. 2, inciso III, define maus-tratos "qualquer ato, direto ou indireto, comissivo ou omissivo, que intencionalmente ou por negligência, imperícia ou imprudência provoque dor ou sofrimento desnecessário aos animais" (Brasil, 2018), portanto a classificação na esfera administrativa é subjetiva, dependendo assim das análises técnico-científicas dos peritos para adequada classificação. Dessa forma, constata-se a relevância do perito com formação em Medicina Veterinária para atestar que a dor ou o sofrimento foram desnecessários ao animal a partir de conhecimentos específicos.

\section{Exploração clínica forense}

Em animais de produção, incluindo os bovinos, o bem-estar constitui uma preocupação de ordem mundial. Na prática da clínica médica, o médico veterinário pode suspeitar de patologias que não estão relacionadas às contingências do manejo de rotina, sendo frequentes, práticas de maus-tratos, crueldades, abusos e emprego de técnicas arcaicas, sendo algumas de sintomatologias despercebidas ou até ocultadas pelos proprietários e funcionários, reveladas apenas pelo médico veterinário durante exames clínicos de rotina. Em animais de produção, o bem-estar vem sendo debatido do ponto de vista econômico, científico e social, o que torna uma questão importante para contribuir com a definição de protocolos de diagnósticos bem fundamentados. Na prática, vários procedimentos podem ser combinados e discutidos para definir pontos críticos e elaborar protocolos diagnósticos de bem-estar, de acordo com o manejo de cada região ou propriedade. Estes protocolos são compreendidos por indicadores fisiológicos, ambientais, nutricionais, comportamentais e sanitários, além dos exames complementares, sendo relevantes quando se pretende definir regulamentação de uma legislação específica (Bond et al., 2012). Algumas enfermidades se destacam pela importância da alta incidência, entre elas a mastite bovina e as podopatias, embora já existam conhecimentos científicos necessários para o controle e prevenção (Bradley, 2002; Greenough, 2007).

Para conhecer o grau de bem-estar de forma científica é mister a elaboração de técnicas de diagnóstico. A realização de um exame clínico minucioso é importante, tanto para estabelecer diagnóstico, tratamento e prognóstico, quanto para constatar maus-tratos em bovinos quando associado a uma conduta dolosa do agente. Este exame torna-se necessário pela incapacidade do animal de se comunicar com o homem e pelo fato de muitas vezes a queixa principal não corresponde com o problema real do animal. O exame clínico permite uma avaliação precisa da evolução clínica do animal, possibilita a análise de outros sistemas não relacionados com a queixa principal e, determina o diagnóstico diferencial, já que os mesmos sintomas podem se manifestar em diferentes enfermidades. O exame clínico geral constitui o passo decisivo para realização do exame clínico especial dos sistemas do corpo (Feitosa, 2014). Dessa maneira, a realização do mesmo tem fundamental importância para o diagnóstico da síndrome de maus-tratos, de imperícia, negligência e imprudência, destacando-se a relevância dos trabalhos dos peritos, em número suficiente para atender esta demanda profissional. De acordo com Arkow \& Nassaro (2017) e Hammerschimidt \& Molento (2017) existe a necessidade da fundação de um Instituto Médico Legal Veterinário para atender esta demanda na área criminal, por exemplo. Por outro lado, o sistema produtivo agropecuário também requer um olhar crítico, pois dependendo do contexto pode ser considerado um local de crime, um corpo de delito a ser examinado. A observação das instalações, manejo sanitário, nutricional, reprodutivo também revelam informações cruciais para a exploração clínica forense. O grau de bem-estar e manejos éticos deve ser considerado desde o nascimento do animal, mesmo que este não tenha um valor monetário significativo no processo produtivo, como bezerros machos em fazendas leiteiras. Mas ainda assim sua dignidade deve ser respeitada. $\mathrm{O}$ dimensionamento adequado das instalações para criação artificial de bezerras leiteiras é fundamental e pode ser delineado de maneira coletiva ou individual. A escolha do tipo correto favorece o controle da saúde, o manejo adequado e as necessidades comportamentais dos animais, destacando o modelo coletivo que contribui para o desenvolvimento e socialização (Dawkins, 2017; Fraser, 2009; Koknaroglu \& Akunal, 2013). O índice de necessidade dos animais está fundamentado na avaliação e adequação das instalações em relação às suas necessidades. Bezerros confinados em gaiolas muito pequenas ou até gaiolas metabólicas não conseguem expressar seu comportamento natural devido à restrição do espaço. $\mathrm{O}$ conhecimento sobre sofrimento animal associado às doenças é escasso, embora 
lesões e limitações dos movimentos de liberdades são indicativas que levam ao baixo grau de bem-estar (Broom \& Molento, 2004).

Em ambientes artificiais que restrinjam comportamentos de elevada motivação, há comprometimento com presença de comportamento estereotipado, levando a redução do grau de bemestar animal (Broom \& Johnson, 1993; Carenzi \& Verga, 2009; Koknaroglu \& Akunal, 2013; Waterhouse, 1996). Os bezerros são submetidos ao distresse e isolamento social como consequência do desmame, levando a comportamentos estereotipados como sugar outros bezerros ou instalações, rolar de língua (Passillé \& Rushen, 2006). Existem modelos de criação nos quais os bezerros são mantidos presos por correntes fixadas no solo cujas extremidades conectam as coleiras fixadas nos animais (Figura 3B), existindo ainda os modelos variáveis, onde as correntes são fixadas em um fio, permitindo as movimentações tipo "vai e vem". Todos estes modelos permitem que os animais tenham acesso a um abrigo, tipo casinhas, para proteger do sol e das intempéries. Embora, alguns modelos de casinhas apresentem as vantagens como proteção das intempéries e possibilidades de deslocar das áreas contaminadas, muitas delas são inadequadas, por não dispor de proteções laterais e no fundo, predispondo as doenças, notadamente as respiratórias. Independente do modelo estas instalações restringem os movimentos de liberdades e afetam o comportamento natural dos animais, pelo fato de impedir as atividades lúdicas e a socialização entre eles. Neste contexto, deve-se dar preferência aos modelos de alojamentos que não afetem o comportamento natural e a qualidade de vida dos bezerros.

\section{Maus-tratos e bem-estar em bovinos}

A preocupação com o meio ambiente está contemplada na Constituição Federal de 1988 no seu Art. 225: "Todos têm direito ao meio ambiente ecologicamente equilibrado, bem de uso comum do povo e essencial à sadia qualidade de vida, impondo-se ao poder público e à coletividade o dever de defendêlo e preservá-lo para as presentes e futuras gerações" (Brasil, 1988). A vedação ao sofrimento animal é destacada no $\$ 1^{\circ}$ inciso VII: "proteger a fauna e a flora, vedadas, na forma da lei, as práticas que coloquem em risco sua função ecológica, provoquem a extinção de espécies ou submetam os animais a crueldade" (Brasil, 1988).

No Brasil os casos de maus-tratos aos animais estão sujeitos às sanções penais e administrativas, através da Lei de Crimes Ambientais, Lei no 9.605/98. O Capítulo V, Art. 32 define: "Praticar ato de abuso, maustratos, ferir ou mutilar animais silvestres, domésticos ou domesticados, nativos ou exóticos. Pena-detenção, de três meses a um ano, e multa". Apesar de não estar explícito no texto legislativo, esta conduta criminal deve ser dolosa. Ou seja, o autor tem que ter consciência dos seus atos, ter intenção, querer o resultado (dolo direto) ou assumir o risco de produzi-lo (dolo eventual). Neste capítulo, está definido no $§ 1^{\circ}$ "incorre nas mesmas penas quem realizar experiência dolorosa ou cruel em animal vivo, ainda que para fins didáticos ou científicos, quando existem recursos alternativos". No § $2^{\circ}$ "A pena é aumentada de um sexto a um terço, se incorre morte do animal" (Brasil, 1998). A Lei $\mathrm{n}^{\circ}$ 11.794/08 estabelece critérios para a criação e a utilização de animais em atividades de ensino e pesquisa científica, em todo território nacional. No Art. $4^{\circ}$ desta Lei foi criado o Conselho Nacional de Controle de Experimentação Animal - CONCEA, o qual tem a competência de formular e zelar pelo cumprimento das normas relativas à utilização humanitária de animais com a finalidade de ensino e pesquisa. No Capítulo III criaram-se as Comissões de Éticas dos Animais CEUAs, com seu regimento e sua competência estabelecida nos Art. $8^{\circ}, 9^{\circ}$ e $10^{\circ}$ (Brasil, 2008). Tem sido observado, na prática de rotina e de forma irresponsável, que existem bovinos sendo utilizados em experimentos científicos sem a devida preocupação com o bem-estar animal. Ressalta-se que diversas patologias e condições clínicas, que de forma direta ou indireta, podem influenciar os resultados de um experimento. Por este motivo, no regimento da CEUA consta no Capítulo 2, Art. $14^{\circ}$ "o animal só poderá ser submetido às intervenções recomendadas nos protocolos dos experimentos que constituem a pesquisa ou programa de aprendizado quando, antes, durante e após o experimento, receber cuidados especiais", conforme estabelecido pelo CONCEA. Ultimamente diversas instituições de ensino foram denunciadas por supostas práticas de maus tratos em ambiente acadêmico e, por isso, mais uma vez se faz necessário o médico veterinário perito para elucidação dos fatos.

É crescente o clamor social por penas mais altas para crimes cruéis contra animais e maior cobrança da atuação da fiscalização nas esferas municipais e estaduais. Neste sentido, a partir dos anos 2000 diversas cidades e estados também legislaram conceituando maus tratos e estabeleceram sanções 
administrativas que vão desde advertência, multa até mesmo a apreensão do animal. A partir dos conceitos expostos acima foram confeccionados dois organogramas e uma prancha de fotos exemplificativa para auxiliar o médico veterinário na elaboração de documentos para fins periciais em bovinos nas esferas civil, criminal e administrativa.

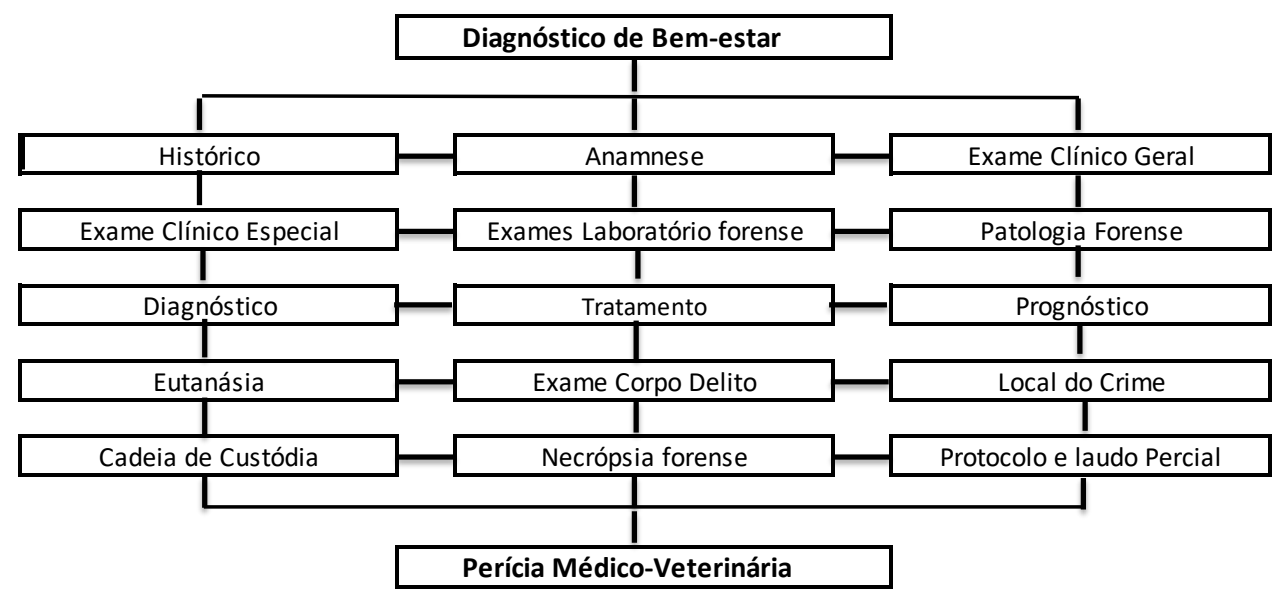

Figura 1. Diagnóstico de bem-estar: organograma da fundamentação da exploração clínica forense em bovinos na perícia médico-veterinária. Quando a perícia também permitir a identificação de conduta dolosa será configurado o crime de maus tratos.

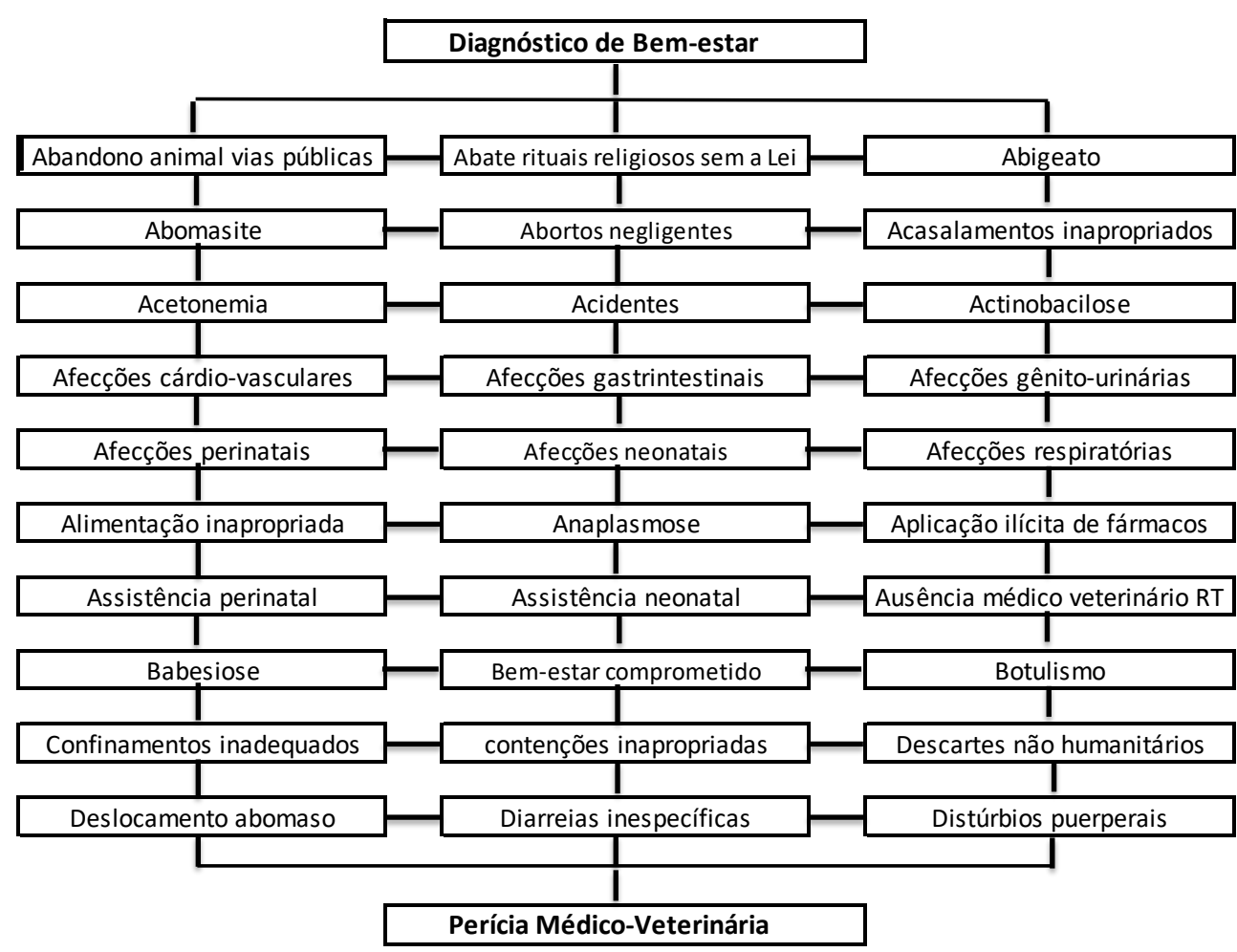

Figura 2. Organogramas dos principais pontos críticos, fatores de riscos e condições clínico-patológicas forenses em bovinos que, quando associados ou não, podem ser envolvidos direta ou indiretamente na constatação de baixo bem-estar e síndrome de maus-tratos em bovinos. Quando a perícia também permitir a identificação de conduta dolosa será configurado o crime de maus tratos. 


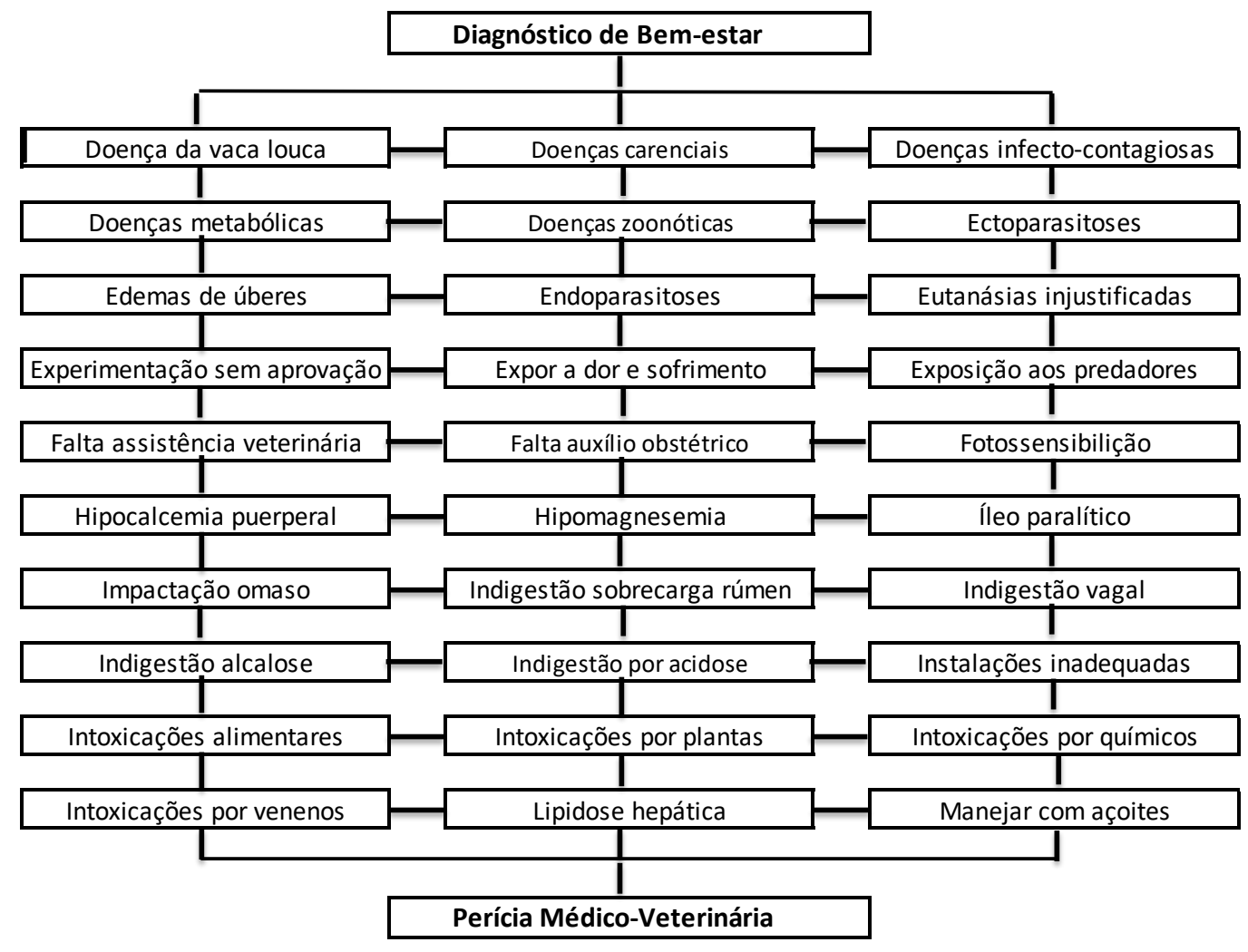

Figura 2. Continuação

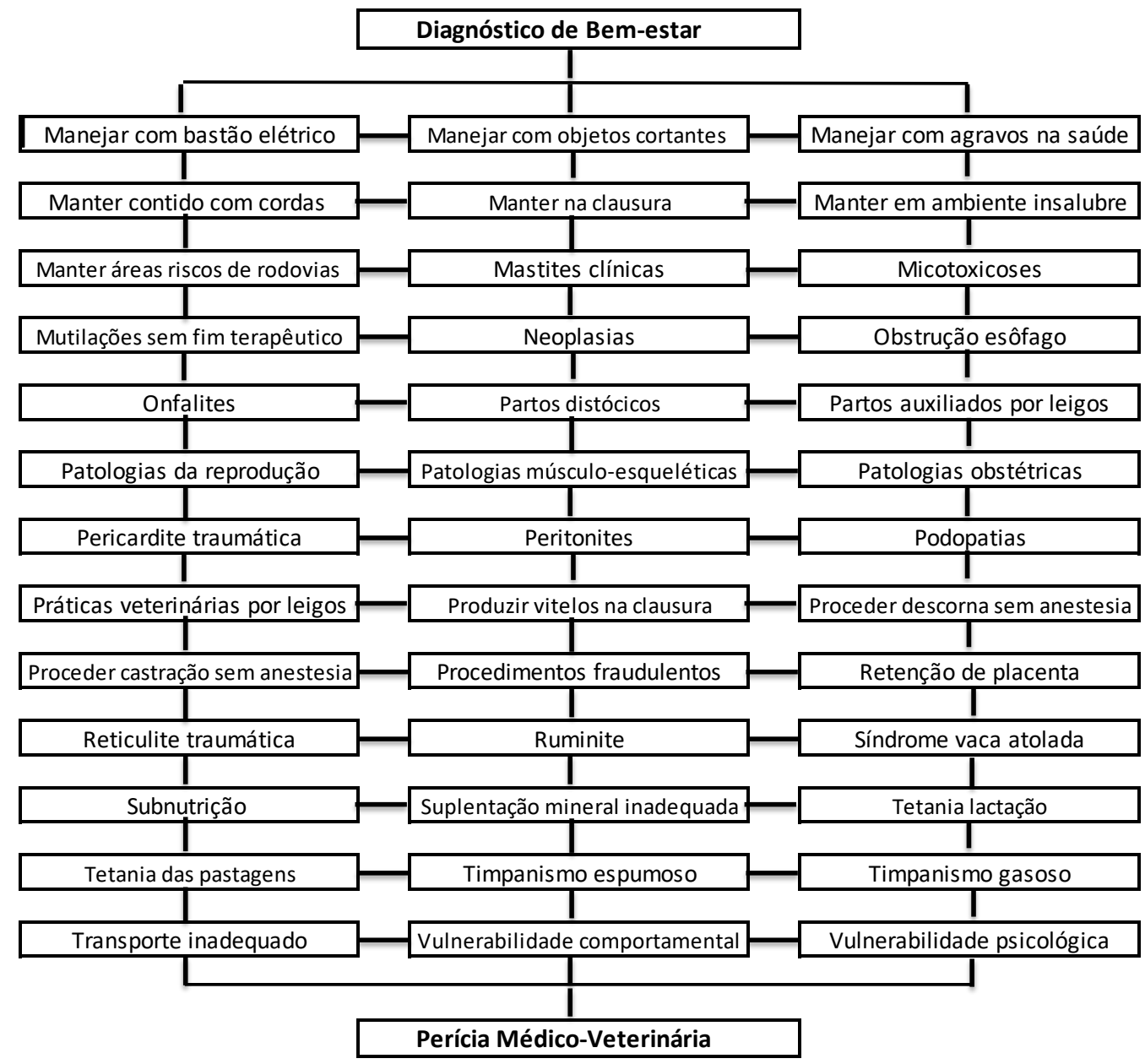

Figura. 2 Continuação 


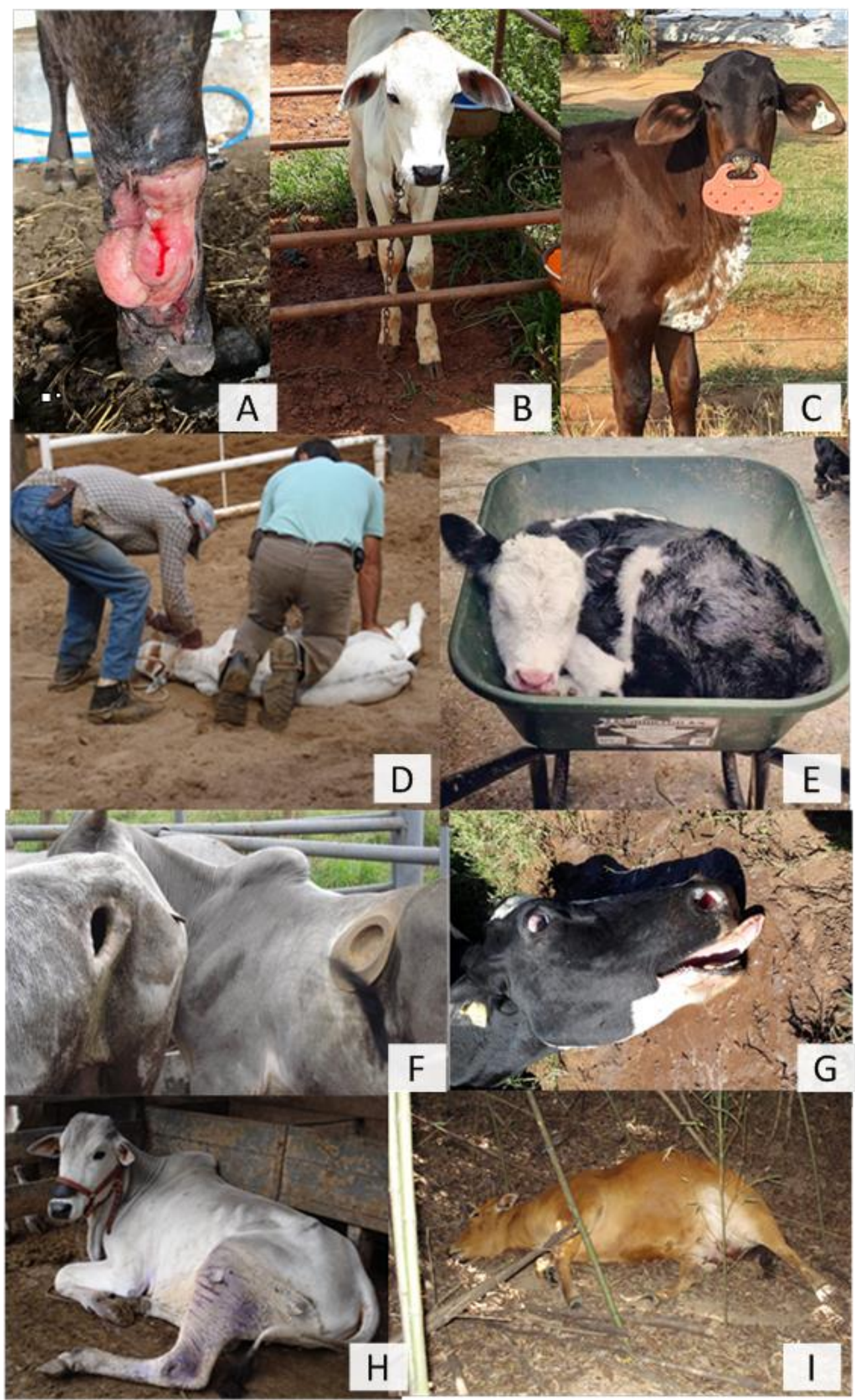

Figura. 3 Ilustrações indicadas de "A" a "I" de lesões classificadas pela traumatologia forense e condições de manejo não compatíveis com bem-estar de bovinos, levando a sofrimento em casos extremos. (A): lesão extensa e granulomatosa decorrente de trauma físico, membro pélvico, metatarso direito; (B): manutenção de recém-nascido acorrentado; (C): uso de tabuleta nasal de desmame; (D): contensão inadequada de bezerro; (E): separação abrupta do recém-nascido; (F): sequela de fístula ruminal, rúmen aberto, sem a cânula de fechamento; (G): animal negligenciado em estado comatoso; (H): lesões traumáticas no membro pélvico devido a instalações e (I): óbito de vaca decorrente de distocia negligenciada, com feto insinuado na via fetal mole. 


\section{Discussão}

Em animais de produção a terapêutica de doenças tem como fundamento maximizar o desempenho animal e reduzir o máximo possível os custos de produção, destacando o valor econômico do animal. Porém, o médico veterinário tem suas atividades pautadas no Código de Ética Veterinário, Resolução 1.138/16, destacando dentre os princípios fundamentais, o artigo $3^{\circ}$ e $4^{\circ}$, respectivamente: "empenharse para melhorar as condições de bem-estar, saúde animal, humana, ambiental e os padrões de serviços médicos veterinários; no exercício profissional, usar procedimentos humanitários preservando o bemestar animal evitando sofrimento e dor". Assim, condutas antiéticas, independente de dolo ou culpa são passíveis de penalidade na esfera administrativa. Mesmo que o profissional vivencie práticas cruéis culturalmente arraigadas nos processos produtivos nada justifica o não tratamento digno ao animal durante toda a sua existência. Ainda que o médico veterinário não seja o executor de práticas que incorram em baixo bem-estar, uma vez na qualidade de responsável técnico, ele poderá ser responsabilizado também na esfera cível. As ilustrações de A a I, da figura 3 revelam situações rotineiramente encontradas em sistemas pecuários. Os bovinos estão sujeitos, de forma direta ou indireta, a diversas lesões traumáticas ou condições patológicas, sendo elas de ordens susceptíveis, vulneráveis, acidentais ou intencionais (Figura 2 e Figura 3 A, F, G, H e I). Por esse motivo, podem resultar em processos judiciais para determinação de sua causa e apuração de responsabilidade/autoria.

Tanto a discussão como a elaboração de um laudo pericial é considerada atividade de fundamental importância na exposição e esclarecimento da verdade, devendo ser realizada de maneira cautelosa, metódica e objetiva (Cervo et al., 2007). As investigações cíveis e criminais contra bovinos não está fora deste contexto, tendo em vista que perante a legislação não existe distinção entre os animais de companhia e os de produção. Ambos são seres sencientes e com altas capacidades cognitivas, sendo comprovadas por diversos trabalhos da literatura nacional e internacional. Portanto, a avaliação de bemestar e maus-tratos tem o mesmo eixo central, pois as necessidades desses grupos de indivíduos são as mesmas. A elaboração do laudo pericial é um documento de grande importância no estudo da criminalística, considerando que o mesmo evidencia a prova material de um delito. Contudo, para a constatação de prática criminal também é necessário à comprovação do dolo. Por sua vez, esta conduta não pode ser apenas inferida é necessária sua comprovação por meios de provas. Os protocolos de perícia em bem-estar animal apresentam limitações para a apuração relativas às intenções humanas que geralmente não compõem o corpo de delito. A metodologia de exploração clínica forense aqui delineada permite auxiliar o perito médico veterinário a confeccionar um laudo pericial objetivo, técnico e imparcial a partir de uma avaliação sistêmica do animal e do ambiente. Salienta-se a complexidade e grande diversidade dos sistemas pecuários brasileiros e, com a compilação dos principais aspectos abordados nas figuras 1 e 2, o trabalho executado será minucioso detalhado e ao mesmo tempo abrangente.

Notadamente as espécies submetidas a sistemas intensivos de exploração, ainda falta sentimentos de respeito e empatia mesmo nas propriedades mais técnica. A prevalência dos principais problemas clínico-patológicos e dos fatores de riscos relacionados aos modelos físicos dos sistemas de criação dos bovinos, em especial dos bovinos leiteiros, leva a crer que eles interferem de forma marcante no diagnóstico e na prevenção do baixo bem-estar. O conjunto desses fatores são requisitos em potencial para a peritagem médico-veterinária, com ênfase naqueles que contribuem de forma significativa pela modalidade de culpa por responsabilidade profissional (negligência, imperícia e imprudência).

\section{Conclusão}

Diante do exposto, conclui-se que esta revisão científica compila os principais pontos críticos em uma abordagem sistêmica que podem ser utilizados por médicos veterinários peritos na realização de perícias com embasamento técnico-científico. Sua abrangência recai tanto nas questões de bem-estar quanto nas de maus-tratos em bovinos. Neste sentido, a ciência da criminalística tem fundamentação no mundo da investigação criminal científica, devendo os peritos tomar consciência da importância dos seus trabalhos no contexto da aplicação da justiça, independente da espécie investigada. Já nas esferas civil e administrativa, também existem implicações legais na qual o médico veterinário tem papel central. Espera-se que com o enfrentamento jurídico de estudos e pesquisas focados neste tema, seja fomentada uma visão realista e crítica dos sistemas de criação de bovinos e consequentemente uma 
avaliação adequada do bem-estar e manejo humanitário destes animais. Assim como contribuir para a responsabilização em processos judiciais daqueles que deveriam zelar pelos animais.

\section{Referências Bibliográficas}

Arkow, P. \& Nassaro, M. R. F. (2017). Maus-tratos a animais no contexto de outra violência familiar. In R. A. Tostes, Reis, S. T. J. \& V. V. Castilho (Eds.), Tratado de Medicina Veterinária Legal. Curitiba, Paraná, Brasil. : Medvep.

Bond, G., B., Almeida, R., Ostrensky, A. \& Molento, C. F. M. (2012). Métodos e pontos críticos de bem-estar de bovinos leiteiros. Ciência Rural, 421286-1293. doi: https://doi.org/10.1590/S010384782012005000044.

Bradley, A. J. (2002). Bovine mastitis: an evolving disease. The Veterinary Journal, 164(2):116-128.

Brasil, Constituição da República Federativa do Brasil de 1988, Art. 225, Cap. VI do Meio Ambiente. http://www.planalto.gov.br/ccivil_03/constituicao/constituicaocompilado.htm [Acesso 09 de Dez de 2019].

Brasil, Legislação do Conselho Federal de Medicina Veterinária - CFMV, Resolução no 1236, de 26 de outubro de 2018. Define e caracteriza crueldade, abuso e maus-tratos contra animais vertebrados. Dispõe sobre a conduta de médicos veterinários e zootecnistas e dá outras providências. http://portal.cfmv.gov.br/lei/index/id/903 [Acesso 25 de Mar 2019].

Brasil, Lei Federal 11.794, de 8 de outubro de 2008. Regulamenta o inciso VII do $\S 1^{\circ}$ do Art. 225 da constituição Federal, estabelecendo procedimentos para o uso científico de animais; revoga a lei ${ }^{\circ}$ 6.638, de 8 de maio de 1.979; e dá outras providências. http://www.planalto.gov.br/ccivil_03/_ato2007-2010/2008/lei/111794.htm [Acesso 28 de Mar de 2019].

Brasil, Lei 13.105, de 16 de março de 2015. Dispõe sobre as normas processuais civis. http://www.planalto.gov.br/ccivil_03/_ato2015-2018/2015/lei/113105.htm [Acesso em 09 de Dez de 2019].

Brasil, Lei 5.517, de 23 de Outubro de 1968. Dispõe sobre o exercício da profissão de médico veterinário e cria os Conselhos Federal e Regionais de Medicina Veterinária. http://www.planalto.gov.br/ccivil_03/Leis/L5517.htm. [Acesso 11 de Abr de 2019].

Brasil, Lei 8.078, de 11 de setembro de 1990. Dispõe sobre a proteção do consumidor e dá outras providências. https://www2.camara.leg.br/legin/fed/lei/1990/lei-8078-11-setembro-1990-365086normaatualizada-pl.pdf [Acesso em 09 de Dez de 2019].

Brasil, Lei 9.605, de 12 de fevereiro de 1998, Lei de Crimes Ambientais. Dispõe sobre as sanções penais e administrativas derivadas de condutas e atividades lesivas ao meio ambiente, e dá outras providências. http://www.planalto.gov.br/ccivil_03/LEIS/L9605.htm [Acesso 28 de Mar de 2019].

Brasil, Resolução 1.138, de 16 de dezembro de 2016. Aprova o código de ética do Médico Veterinário. http://portal.cfmv.gov.br/uploads/reso\%201138_2016\%20portal\%20cfmv\%20(3).pdf [Acesso 09 de Dez de 2019].

Brasil, Resolução 722, de 16 de Agosto de 2002. Aprova o Código de Ética do Médico Veterinário. http://www.crmvpa.org.br/arquivos/File/RESO\%20722_2002Aprova\%20o\%20C\%C3\%B3digo\%20de\%20\%C3\%89tica\%20do\%20M\%C3\%A9dico\%20Veterin \%C3\%A1rio.pdf. [Acesso 20 de Jun de 2019].

Broom, D. M. \& Johnson, K. G. (1993). Stress and animal welfare. London: Springer Science \& Business Media.

Broom, D. M. \& Molento, C. F. M. (2004). Animal welfare: concept and related issues-review. Archives of Veterinary Science, 9(2):1-11.

Carenzi, C. \& Verga, M. (2009). Animal welfare: review of the scientific concept and definition. Italian Journal of Animal Science, 8(1):21-30.

Cervo, A. L., Bervian, P. A. \& Silva, R. (2007). Metodologia científica (6 ed. ed. Vol. 1). São Paulo: Pearson Prendice Hall. 
Conceição, C. D. C., Almeida, E. C. P. \& Marcon, F. M. (2017). Novo código de ética médica veterinária - Comentários sobre a ótica pericial. Salvador, Bahia.

Costa, L. R. S. \& Costa, B. M. C. (2015). A perícia médico-legal aplicada à área criminal. Campinas, São Paulo, Brasil.: Ediitora Millennium.

Dawkins, M. S. (2017). Animal welfare and efficient farming: is conflict inevitable? Animal Production Science, 57(2):201-208.

Feitosa, F. L. F. (2014). Semiologia veterinária: A arte do diagnóstico. São Paulo: Grupo Gen-Editora Roca Ltda.

Figueiredo, A. M. (2009). Perito judicial - Aspectos jurídicos - Responsabilidade civil e criminal. Rio de Janeiro, Rio de Janeiro, Brasil.: Lumen Juris.

Fraser, D. (2009). Animal behaviour, animal welfare and the scientific study of affect. Applied Animal Behaviour Science, 118(3-4):108-117. doi: http://dx.doi.org/10.1016/j.applanim.2009.02.020

Garcia, R. C. M. (2017). Desafios para o enfrentamento da negligência. In R. A. Tostes, S. T. J. Reis \& V. V. Castilho (Eds.), Tratado de medicina veterinária legal. Curitiba, Paraná, Brasil: Medvep.

Greenough, P. R. (2007). Bovine laminitis and lameness: a hands on approach. Philadelphia: Elsevier Health Sciences.

Guimarães, M. A. (2017). Medicina legal. In J. A. Velho, G. C. Geiser \& A. Espindula (Eds.), Ciências Forenses: uma introdução às principais áreas da criminalística moderna. Campinas, São Paulo, Brasil: Millenium Editora.

Hammerschimidt, J. \& Molento, C. F. M. (2017). Perícia em bem-estar animal nos crimes de maustratos contra animais. In R. A. Tostes, S. T. J. Reis \& V. V. Castilho (Eds.), Tratado de medicina veterinária legal. Curitiba, Paraná, Brasil. : Medvep.

Hammerschmidt, J. \& Molento, C. F. M. (2017). Perícia em bem-estar animal nos crimes de maus-tratos contra animais. In R. A. Tostes, S. T. J. Reis \& V. V. Castilho (Eds.), Tratado de Medicina Veterinária Legal. Curitiba, Paraná, Brasil: Medvet.

Koknaroglu, H. \& Akunal, T. (2013). Animal welfare: An animal science approach. Meat Science, 95(4):821-827. doi: http://dx.doi.org/10.1016/j.meatsci.2013.04.030

Maiorka, P. C. (2016). Medicina Veterinária Legal: uma demanda crescente da sociedade. Revista do Conselho Regional do Estado de São Paulo, 6110-18.

Passillé, A. M. B. \& Rushen, J. (2006). Calves' behaviour during nursing is affected by feeding motivation and milk availability. Applied Animal Behaviour Science, 101(3-4):264-275. doi: http://dx.doi.org/10.1016/j.applanim.2006.02.007

Reis, S. T. J. (2017). Perícia de local de crime envolvendo animais - Parte I. In R. A. Tostes, S. T. J. Reis \& V. V. Castilho (Eds.), Tratado de medicina veterinária legal. Curitiba, Paraná, Brasil: Medvep.

Rocha, N. S. (2017). Corpo de delito e processos por erro médico veterinário. In R. A. Tostes, S. T. J. Reis \& V. V. Castilho (Eds.), Tratado de medicina veterinária legal. Curitiba, Paraná, Brasil: Medvep.

Santiago, E. (2014). Criminalística comentada: exposição e comentários de temas periciais e assuntos correlatos - questões polêmicas - temas controvertidos. Campinas, São Paulo, Brasil: Millennium.

Slowinski, K., Tremori, T. M., Massad, M. R. R., Tasaka, A. C. \& Rocha, N. S. (2016). Responsabilidade ética e civil do médico-veterinário no ambiente hospitalar. Revista de Educação Continuada em Medicina Veterinária e Zootecnia do CRMV-SP, 14(2):30-37.

Tostes, R. A. \& Reis, S. T. J. (2017). História da medicina veterinária legal - Parte II. In R. A. Tostes, S. T. J. Reis \& V. V. Castilho (Eds.), Tratado de medicina veterinária legal. Curitiba, Paraná, Brasil: Medvep.

Tremori, T. M., Ribas, L. M., Massad, M. R. R., Reis, S. T. J., Pinto, A. C. F. \& Rocha, N. S. (2018). Classificação comparada das lesões de ordem mecânica segundo a traumatologia forense no exame de corpo de delito em animais. Revista Brasileira de Criminalística, 7(2):20-25. 
Tremori, T. M. \& Rocha, N. S. (2013). Exame do corpo de delito na Perícia Veterinária (ensaio). Revista de Educação Continuada em Medicina Veterinária e Zootecnia do CRMV-SP, 11(3):30-35.

Velho, J. A., Geiser, G. C. \& Espindula, A. (2017). Ciências Forenses: Uma introdução às principais áreas da criminalística moderna. Campinas, São Paulo: Millenium Editora.

Waterhouse, A. (1996). Animal welfare and sustainability of production under extensive conditions-a European perspective. Applied Animal Behaviour Science, 49(1):29-40.

Recebido: 9 de setembro, 2019.

Aprovado: 8 de novembro, 2019

Publicado: 28 de janeiro, 2020.

Licenciamento: Este artigo é publicado na modalidade Acesso Aberto sob a licença Creative Commons Atribuição 4.0 (CC-BY 4.0), a qual permite uso irrestrito, distribuição, reprodução em qualquer meio, desde que o autor e a fonte sejam devidamente creditados. 